\title{
Risk of adverse events among older adults following co-prescription of clarithromycin and statins not metabolized by cytochrome P450 3A4
}

\author{
Daniel Q. Li BSc, Richard Kim MD, Eric McArthur MSc, Jamie L. Fleet BHSc, David G. Bailey PhD, \\ David Juurlink MD PhD, Salimah Z. Shariff PhD, Tara Gomes MHSc, Muhammad Mamdani PharmD MPH, \\ Sonja Gandhi BSc, Stephanie Dixon PhD, Amit X. Garg MD PhD
}

See also commentary on page 163 and at www.cmaj.ca/lookup/doi/10.1503/cmaj.150030

Competing interests: Tara Gomes has received grant funding for the Ontario Drug Policy Research Network from the Ontario Ministry of Health and Long-Term Care. Muhammad Mamdani serves on CMAJ's Editorial Advisory Board (but had no role in the decision to publish this paper) and has been on advisory boards for AstraZeneca, BristolMyers Squibb, Eli Lilly and Company, GlaxoSmithKline,

Hoffman-La Roche,

Novartis, Novo Nordisk and Pfizer. Amit Garg received an investigator-initiated grant from Astellas and Roche to support a Canadian Institutes of Health Research study involving living kidney donors; his institution received unrestricted research funding from Pfizer. No other competing interests were declared.

This article has been peer reviewed.

Correspondence to: Amit Garg, amit.garg@lhsc.on.ca

CMAJ 2015. DOI:10.1503 /cmaj.140950

\section{ABstract}

Background: The cytochrome P450 3A4 (CYP3A4) inhibitor clarithromycin may also inhibit liverspecific organic anion-transporting polypeptides (OATP1B1 and OATP1B3). We studied whether concurrent use of clarithromycin and a statin not metabolized by CYP3A4 was associated with an increased frequency of serious adverse events.

Methods: Using large health care databases, we studied a population-based cohort of older adults (mean age 74 years) who were taking a statin not metabolized by CYP3A4 (rosuvastatin [76\% of prescriptions], pravastatin [21\%] or fluvastatin [3\%]) between 2002 and 2013 and were newly prescribed clarithromycin $(n=51523)$ or azithromycin ( $n=52518$ ), the latter an antibiotic that inhibits neither CYP3A4 nor OATP1B1 and OATP1B3. Outcomes were hospital admission with a diagnostic code for rhabdomyolysis, acute kidney injury or hyperkalemia, and allcause mortality. All outcomes were assessed within 30 days after co-prescription.

$O$ tatins may soon be recommended for more than a billion people worldwide. ${ }^{1} \mathrm{Al}-$ though past clinical trials have generally proven statins to be safe, ${ }^{2}$ a 2012 Internet-based survey suggested that almost one-third of statin users experience adverse effects. ${ }^{3}$ In a small number of individuals, statin use has been associated with serious effects, including rhabdomyolysis, acute kidney injury, hyperkalemia and death. ${ }^{4-6}$ The risk of statin toxicity increases with higher blood statin concentrations, which can arise when concurrent medications alter the pharmacokinetics of statins. ${ }^{7}$ Traditional pharmacokinetic models attribute this increase to the inhibition of the drug-metabolizing enzyme cytochrome P450 3A4 (CYP3A4).

More recent evidence supports an additional cause that involves reduced drug transporter-
Results: Compared with the control group, patients co-prescribed clarithromycin and a statin not metabolized by CYP3A4 were at increased risk of hospital admission with acute kidney injury (adjusted relative risk [RR] 1.65, $95 \%$ confidence interval $[\mathrm{Cl}] 1.31$ to 2.09 ), admission with hyperkalemia (adjusted RR $2.17,95 \% \mathrm{Cl} 1.22$ to 3.86 ) and all-cause mortality (adjusted RR $1.43,95 \% \mathrm{Cl} 1.15$ to 1.76 ). The adjusted RR for admission with rhabdomyolysis was 2.27 (95\% Cl 0.86 to 5.96 ). The absolute increase in risk for each outcome was small and likely below $1 \%$, even after we considered the insensitivity of some hospital database codes.

Interpretation: Among older adults taking a statin not metabolized by CYP3A4, coprescription of clarithromycin versus azithromycin was associated with a modest but statistically significant increase in the 30-day absolute risk of adverse outcomes.

mediated hepatic uptake of statins. ${ }^{8-13}$ For example, several haplotypes of commonly occurring genetic polymorphisms in the liver-specific organic anion-transporting polypeptide 1B1 (OATP1B1) were associated with increased blood concentrations of the non-CYP3A4metabolized statins rosuvastatin and pravastatin in humans. ${ }^{13-16}$ Clarithromycin has been shown to inhibit OATP1B1 and OATP1B3 in hepatocyte cell cultures. ${ }^{10}$ However, we found no data to show the effect of clarithromycin on the clinical pharmacokinetics of rosuvastatin, pravastatin and fluvastatin.

All of these findings provided us with the opportunity to investigate the interaction between clarithromycin and statins not metabolized by CYP3A4 in the context of frequency of serious adverse events. ${ }^{17}$ We compared the 
risk of statin-associated adverse events (rhabdomyolysis, acute kidney injury, hyperkalemia and death) when rosuvastatin, pravastatin or fluvastatin is co-prescribed with clarithromycin (a macrolide antibiotic and inhibitor of OATPs ${ }^{18-20}$ ) versus azithromycin (a macrolide antibiotic that does not inhibit OATPs ${ }^{10}$ ).

\section{Methods}

\section{Study design and setting}

We conducted a population-based, retrospective cohort study at the Institute for Clinical Evaluative Sciences (ICES) according to an established protocol approved by the Research Ethics Board at the Sunnybrook Health Sciences Centre (Toronto, Canada). Data on adults 66 years of age and older between June 2002 and March 2013 were obtained and analyzed through linked health care databases in the province of Ontario. The province has about 13.6 million residents, $16 \%$ of whom are 65 years or older and have universal coverage for prescription drugs. ${ }^{21} \mathrm{We}$ followed guidelines for observational studies for the reporting of this study. ${ }^{22}$

\section{Data sources}

We ascertained patient characteristics, drug use, covariate information and outcome data using records from 5 large administrative databases housed at ICES. The Ontario Registered Persons Database contains demographic and vital status information for all residents of the province who have ever been issued a health card. We used the database of the Ontario Drug Benefit Program to identify prescription drug use. The database contains accurate records (error rate $<1 \%$ ) for all outpatient prescriptions dispensed to people 65 years or older. ${ }^{23}$ We obtained detailed diagnostic and procedural information on all hospital admissions in the province, including up to 25 unique diagnostic codes assigned per admission, from the Canadian Institute for Health Information's Discharge Abstract Database. We collected covariate information from the Ontario Health Insurance Plan (OHIP) database. This database includes fee-forservice health claims for inpatient and outpatient physician services. Finally, we obtained information on antibiotic prescribers from the ICES Physician Database, which comprises data from the Corporate Provider Database, the Ontario Physician Human Resource Data Centre database and the OHIP database of physician billings. All of the data were linked anonymously with the use of encrypted health card numbers, a method that has been used previously for studies on adverse drug events, health outcomes and health services. ${ }^{24-29}$

All variables used in this study were complete except for neighbourhood income (missing for $0.25 \%$ of patients) and prescriber specialty (missing for $13.21 \%$ ). We used the International Classification of Diseases, 9th revision (ICD-9) codes before April 2002 and ICD-10 codes after Apr. 1, 2002, to assess baseline comorbidities in the 5 years before the co-prescriptions (Appendix 1, available at www.cmaj.ca/lookup/suppl /doi:10.1503/cmaj.140950/-/DC1). We used ICD-10 codes to ascertain outcomes (Appendix 2, available at www.cmaj.ca/lookup/suppl /doi:10.1503/cmaj.140950/-/DC1), because all events would have occurred after the implementation of this coding system.

\section{Study population}

Our cohort comprised all older adults in Ontario who had continuous prescriptions for statins not metabolized by CYP3A4 (study statins: rosuvastatin, fluvastatin and pravastatin) and who received a co-prescription for either clarithromycin or azithromycin (control group) between June 2002 and March 2013. Azithromycin is an antibiotic with indications similar to those of clarithromycin, but it does not substantially inhibit CYP3A4 or OATP1B1 and OATP1B3.10,30,31 In a previous study of provincial data, we showed that clarithromycin and azithromycin have similar indications, clinical use patterns and rates of adverse events when used independently. ${ }^{32}$ Thus, we felt that the comparison of outcomes among older adults prescribed these antibiotics would serve as a useful model for studying drug interactions in routine clinical practice.

The date of the first co-prescription of a study antibiotic served as the index date. We confirmed that all patients in the study were continuously taking a study statin ( $\geq 2$ prescriptions in the 210 days before the index date) and that the most recent statin prescription covered the index date. This ensured that a study statin and macrolide antibiotic were co-prescribed.

We excluded patients if they met any of the following criteria: (a) they were in their first year of eligibility for provincial coverage of prescription drugs (aged 65 years), to avoid incomplete medication records; (b) they received a prescription for more than one type of antibiotic or statin on the index date, to compare mutually exclusive groups; (c) they received any antibiotic in the 30 days before the index date, to ensure new antibiotic use and to exclude patients with severe infections that failed to respond to initial antibiotic treatment; (d) they had one or more prescriptions for a nonstudy statin (including CYP3A4-metabolized statins) in the 180 days before antibiotic prescription, to ensure that any observed adverse events were associated with the study drugs; (e) they were discharged from hospital in the 2 days before their 
index date, to ensure inclusion of new outpatient antibiotic prescriptions (in Ontario, patients continuing antibiotic treatment started in hospital have their outpatient antibiotic prescription dispensed on the same day or the day after discharge); or (f) they had a prescription for a potent CYP3A4 inhibitor (protease inhibitor, chloramphenicol or antifungal) dispensed in the 6 months before the index date, to exclude drugs that are often also potent inhibitors of OATPs. ${ }^{33,34}$

A patient could be entered into the cohort only once. We restricted analysis to the first prescription of a study antibiotic that the patient received in follow-up (subsequent prescriptions were not considered).

\section{Outcome measures}

We followed patients for 30 days after the index date to assess outcomes. We examined the 4 outcomes specified in a previous study of statin toxicity from drug interactions: ${ }^{24}$ hospital admission because of rhabdomyolysis, admission because of acute kidney injury, admission because of hyperkalemia, and all-cause mortality (the diagnostic codes are shown in Appendix 2). Patients with multiple hospital admission codes were accounted for in the assessment of each type of admission.

In Ontario, we have previously observed that a hospital diagnostic code for rhabdomyolysis identifies patients with a median peak creatine kinase level of 1835 (interquartile range [IQR] 680 to 3986) U/L, whereas the absence of such a code

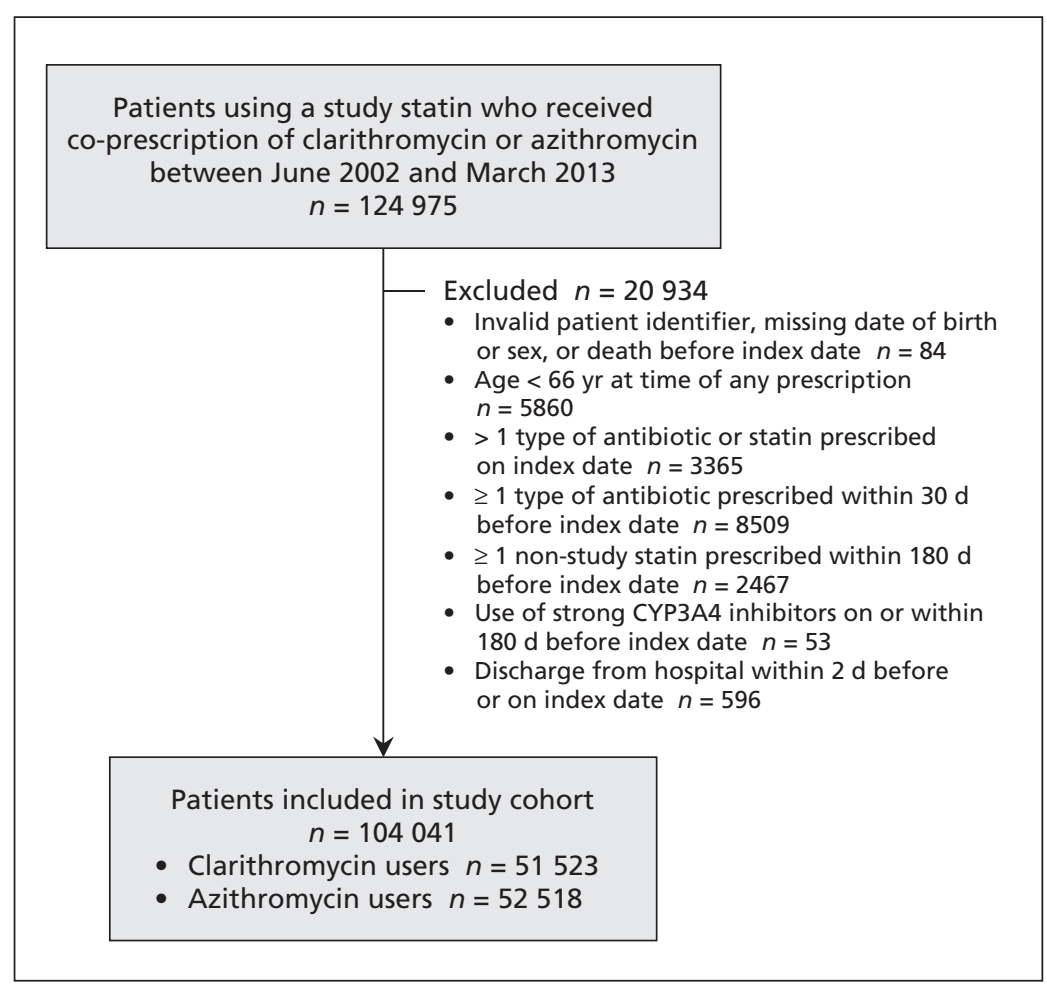

Figure 1: Selection of the study cohort. indicates patients without a creatine kinase level or with a measured median level of 130 (IQR 60 to 368 ) U/L (unpublished data). Similarly, a hospital diagnostic code for acute kidney injury identifies a median absolute increase in serum creatinine of 98 (IQR 43 to 200) $\mu \mathrm{mol} / \mathrm{L}$ from the most recent value before admission, and the absence of such a code represents a median increase of 6 (IQR -4 to 20$) \mu \mathrm{mol} / \mathrm{L} .{ }^{35}$ A code for hyperkalemia identifies a median serum potassium concentration of 6.0 (IQR 5.1 to 6.7 ) $\mathrm{mmol} / \mathrm{L}$, and its absence defines a median concentration of 4.1 (IQR 3.8 to 4.5 ) $\mathrm{mmol} / \mathrm{L} .{ }^{36}$ These validation studies showed a spectrum bias in coding: as a condition becomes more extreme, a code is more likely to be present for that diagnosis. The overall incidence is therefore underestimated, particularly for milder forms of the conditions. For example, the incidence of acute kidney injury can be underestimated up to five-fold when assessed by diagnostic code, as compared with laboratory values. ${ }^{35}$

\section{Statistical analysis}

We compared baseline characteristics between statin users co-prescribed clarithromycin and those co-prescribed azithromycin using standardized differences. ${ }^{37,38}$ This metric describes differences between group means relative to the pooled standard deviation and is considered a clinically meaningful difference if greater than $10 \%$. We expressed the risk of an outcome in both relative and absolute terms, and we used multivariable logistic regression analyses to estimate odds ratios and $95 \%$ confidence intervals (95\% CIs). We adjusted for 15 potential confounding variables based on clinical relevance: age, sex, year of cohort entry; baseline evidence of chronic kidney disease, stroke or transient ischemic attack, peripheral vascular disease, coronary artery disease, congestive heart failure, major cancer and diabetes; baseline use, in the 120 days before the index date, of $\beta$-blockers, calcium-channel blockers, diuretics, angiotensin-converting-enzyme inhibitors or angiotensin II receptor blockers, and nonsteroidal anti-inflammatory drugs.

In all outcome analyses, we interpreted 2-tailed $p$ values of less than 0.05 as statistically significant. We interpreted odds ratios as relative risks (RR; appropriate given the incidences observed). We conducted all statistical analyses using SAS version 9.3 (SAS Institute).

\section{Results}

We identified 104041 people who met the eligibility criteria, with almost equal numbers in the clarithromycin ( $n=51523)$ and azithromycin $(n=$ 52518 ) groups (Figure 1). The most commonly 
prescribed statin was rosuvastatin (76\%), followed by pravastatin $(21 \%)$ and fluvastatin $(3 \%)$. Baseline characteristics of the 2 groups were similar, including type and dose of statin used (Table 1). The median dosage was $1000 \mathrm{mg} / \mathrm{d}$ for 10 days for clarithromycin prescriptions and $300 \mathrm{mg} / \mathrm{d}$ for 5 days for azithromycin prescriptions, which was consistent with drug-prescribing references. ${ }^{41} \mathrm{Co}$ prescriptions of study statins and clarithromycin continued to occur in each year of the study period, including the most recent years of data accrual (Table 1).

Patient outcomes are presented in Table 2. Co-prescription of clarithromycin with a study statin was associated with a higher risk of most of the outcomes: hospital admission with acute kidney injury (RR $1.46,95 \%$ CI 1.16 to 1.84 ), hospital admission with hyperkalemia (RR 1.87, 95\% CI 1.05 to 3.32 ) and all-cause mortality (RR 1.32, 95\% CI 1.07 to 1.62). The number of admissions with rhabdomyolysis was limited (clarithromycin 13, azithromycin 6); the confidence intervals around the estimate of this adverse event were wide, and the increase in relative risk was not statistically significant (RR $2.21,95 \%$ CI 0.84 to 5.81 ). All of the results were consistent after adjustment for the confounders (Table 2). The absolute increase in risk for each outcome was small. Even under the assumption that the diagnostic codes underestimated the incidence by five-fold, the absolute increase in risk for each outcome would remain less than $1 \%$.

\section{Interpretation}

In this population-based cohort study, we observed that co-prescription of clarithromycin versus azithromycin in older adults taking a statin not metabolized by CYP3A4 was associated with a modest but statistically significant increase in the absolute risk of hospital admission with acute kidney injury or hyperkalemia and in the absolute risk of all-cause mortality. The population impact of this preventable drugdrug interaction can be considered in the context of the high frequency of clarithromycin and statin co-prescription (rosuvastatin, or Crestor, was the second most commonly dispensed drug in Canada in 2010 ${ }^{42}$ ).

The main mechanism underlying interactions between macrolide antibiotics and statins is often ascribed to the inhibition of the drugmetabolizing enzyme CYP3A4. ${ }^{43-45}$ For this reason, the US Food and Drug Administration (FDA) currently warns against the co-administration of strong CYP3A4 inhibitors, including clarithromycin, with CYP3A4-metabolized
Table 1 (part 1 of 2): Baseline characteristics of patients co-prescribed clarithromycin or azithromycin with a statin not metabolized by CYP3A4

\begin{tabular}{|c|c|c|c|}
\hline \multirow[b]{2}{*}{ Characteristic } & \multicolumn{2}{|c|}{ Antibiotic; no. (\%) or mean \pm SD } & \multirow[b]{2}{*}{$\begin{array}{l}\text { Standardized } \\
\text { difference, \%* }\end{array}$} \\
\hline & $\begin{array}{c}\text { Clarithromycin } \\
n=51523\end{array}$ & $\begin{array}{c}\text { Azithromycin } \\
n=52518\end{array}$ & \\
\hline
\end{tabular}

\section{General}

$\begin{array}{lccc}\text { Age, } y r & 73.5 \pm 6.3 & 73.8 \pm 6.4 & 4 \\ \text { Sex, female } & 27756(53.9) & 28386(54.1) & 0\end{array}$

Sex, female

$27756(53.9)$

$28386(54.1)$

0

Income quintilet

\begin{tabular}{lrrr}
\hline (lowest) & $10708(20.8)$ & $10385(19.8)$ & 3 \\
\hline 2 & $11414(22.2)$ & $11214(21.4)$ & 2 \\
\hline 3 & $10312(20.0)$ & $10624(20.2)$ & 1 \\
\hline 4 & $9783(19.0)$ & $10408(19.8)$ & 2 \\
\hline 5 (highest) & $9180(17.8)$ & $9750(18.6)$ & 2 \\
$\begin{array}{l}\text { Rural residence } \\
\begin{array}{l}\text { Residence in long-term care } \\
\text { facility }\end{array}\end{array} \quad 1204(12.6)$ & $6522(12.4)$ & 1 \\
\hline
\end{tabular}

facility

Year of cohort entry $¥$

\begin{tabular}{lrrrr}
\hline $2002-2003$ & $3911(7.6)$ & $3598(6.9)$ & 3 \\
\hline $2004-2005$ & $6266(12.2)$ & $6175(11.8)$ & 1 \\
\hline $2006-2007$ & $7539(14.6)$ & $6913(13.2)$ & 4 \\
\hline $2008-2009$ & $11006(21.4)$ & $10423(19.8)$ & 4 \\
$2010-2011$ & $15367(29.8)$ & $15421(29.4)$ & 1 \\
\hline 2012 & $7434(14.4)$ & $9948(18.9)$ & 12 \\
Antibiotic prescriber & & & & \\
Family physician & $43293(84.0)$ & $43599(83.0)$ & 3 \\
Internist & $269(0.5)$ & $284(0.5)$ & 0 \\
\hline Surgeon & $200(0.4)$ & $51(0.1)$ & 6 \\
\hline Other & $1552(3.0)$ & $1704(3.2)$ & 1 \\
\hline Missing data & $6209(12.1)$ & $6880(13.1)$ & 3 \\
\hline
\end{tabular}

Charlson Comorbidity

Index§

\begin{tabular}{|c|c|c|c|}
\hline 0 & $38669(75.1)$ & $38870(74.0)$ & 2 \\
\hline 1 & $5556(10.8)$ & $5855(11.1)$ & 1 \\
\hline 2 & $3680 \quad(7.1)$ & $3914 \quad(7.5)$ & 1 \\
\hline$\geq 3$ & $3618 \quad(7.0)$ & 3879 & 1 \\
\hline \multicolumn{4}{|l|}{ Comorbidityๆ } \\
\hline Major cancer** & $6688(13.0)$ & 6919 (13.2) & 1 \\
\hline Chronic kidney disease & $4292 \quad(8.3)$ & $4660 \quad(8.9)$ & 2 \\
\hline Coronary artery disease $\dagger \dagger$ & $19163(37.2)$ & 20903 (39.8) & 5 \\
\hline Diabetes mellitus $\ddagger$ & $14838(28.8)$ & 15116 (28.8) & 0 \\
\hline Heart failure & $6423(12.5)$ & $7023(13.4)$ & 3 \\
\hline Peripheral vascular disease & $1067 \quad(2.1)$ & $1107 \quad(2.1)$ & 0 \\
\hline Stroke or TIA & 1323 & 1567 & 3 \\
\hline \multicolumn{4}{|l|}{ Medication use§§ } \\
\hline ACE inhibitor & $20106(39.0)$ & 20696 (39.4) & 1 \\
\hline ARB & $11930(23.2)$ & $11585(22.1)$ & 3 \\
\hline$\beta$-Blocker & 16357 (31.7) & 17572 (33.5) & 4 \\
\hline Potassium-sparing diuretic & $2395 \quad(4.6)$ & 2487 & 0 \\
\hline Loop diuretic & $5242(10.2)$ & $5677(10.8)$ & 2 \\
\hline NSAID (excluding ASA) & $8978(17.4)$ & $8911(17.0)$ & 1 \\
\hline Thiazide diuretic & $9243(17.9)$ & $9782(18.6)$ & 2 \\
\hline Any diuretic & 15771 (30.6) & 16655 (31.7) & 2 \\
\hline$\beta_{2}$-Agonist & 8905 (17.3) & $8378(16.0)$ & 4 \\
\hline Anticholinergic & $4178 \quad(8.1)$ & 3743 & 4 \\
\hline Corticosteroid & $4083 \quad(7.9)$ & 3917 & 2 \\
\hline
\end{tabular}


Table 1 (part 2 of 2): Baseline characteristics of patients co-prescribed clarithromycin or azithromycin with a statin not metabolized by CYP3A4

\begin{tabular}{|c|c|c|}
\hline & Antibiotic; no. & or mean $\pm S D$ \\
\hline Characteristic & $\begin{array}{c}\text { Clarithromycin } \\
n=51523\end{array}$ & $\begin{array}{c}\text { Azithromycin } \\
n=52518\end{array}$ \\
\hline
\end{tabular}

\section{Health care use in prior year}

Hospital admissions

\begin{tabular}{rrrrrr}
0 & $44677(86.7)$ & $45184(86.0)$ & 2 \\
1 & 5021 & $(9.7)$ & $5272(10.0)$ & 1 \\
\hline 2 & $1211(2.4)$ & 1398 & $(2.7)$ & 2 \\
$\geq 3$ & 614 & $(1.2)$ & 664 & $(1.3)$ & 1
\end{tabular}

Emergency department visits

$\begin{array}{rrrrr}0 & 34922(67.8) & 34983(66.6) & 2 \\ 1 & 9554(18.5) & 9979(19.0) & 1 \\ 2 & 3689(7.2) & 3825 & (7.3) & 0 \\ \geq 3 & 3358(6.5) & 3731 & (7.1) & 2\end{array}$

Family physician visits

\begin{tabular}{|lrrrr|}
\hline 0 & $892(1.7)$ & $1090(2.1)$ & 3 \\
\hline $1-2$ & $3195(6.2)$ & $3135(6.0)$ & 1 \\
\hline $3-4$ & $6438(12.5)$ & $6368(12.1)$ & 1 \\
\hline $5-6$ & $8419(16.3)$ & $8430(16.1)$ & 1 \\
\hline $7-8$ & $7990(15.5)$ & $7726(14.7)$ & 2 \\
\hline $9-10$ & $6148(11.9)$ & $6119(11.7)$ & 1 \\
\hline 11 & $18441(35.8)$ & $19650(37.4)$ & 3 \\
\hline
\end{tabular}

Cardiologist visits

$\begin{array}{rrrrr}0 & 29097(56.5) & 28251(53.8) & 5 \\ 1 & 9656(18.7) & 10003(19.0) & 1 \\ 2 & 4748(9.2) & 5086 & (9.7) & 2 \\ \geq 3 & 8022(15.6) & 9178(17.5) & 5\end{array}$

\section{Procedure}

\begin{tabular}{|lrrrl|}
\hline Echocardiography & $25575(49.6)$ & $27682(52.7)$ & 6 \\
\hline Holter monitoring & $11082(21.5)$ & $12670(24.1)$ & 6 \\
\hline Cardiac stress test & $23822(46.2)$ & $25262(48.1)$ & 4 \\
\hline Carotid endarterectomy & $263(0.5)$ & $317(0.6)$ & 1 \\
\hline Cardiac catheterization & $5558(10.8)$ & $6304(12.0)$ & 4 \\
\hline Carotid ultrasound & $10560(20.5)$ & $11471(21.8)$ & 3 \\
\hline Chest radiograph & $40573(78.7)$ & $41189(78.4)$ & 1 \\
\hline Pulmonary function test & $16293(31.6)$ & $16667(31.7)$ & 0 \\
\hline Statin use & & & \\
\hline Rosuvastatin & $39082(75.9)$ & $40460(77.0)$ & 3 \\
\hline Pravastatin & $11172(21.7)$ & $10931(20.8)$ & 2 \\
\hline Fluvastatin & $1269(2.5)$ & $1127(2.1)$ & 2 \\
\hline Statin daily dose, $\mathbf{m g}$ & & & \\
\hline Rosuvastatin & $12.8 \pm 7.8$ & $12.8 \pm 7.8$ & 1 \\
\hline Pravastatin & $26.0 \pm 12.2$ & $26.2 \pm 12.2$ & 2 \\
\hline Fluvastatin & $36.9 \pm 19.5$ & $37.9 \pm 19.6$ & 5 \\
\hline Note:ACE &
\end{tabular}

Note: $\mathrm{ACE}=$ angiotensin-converting-enzyme, $\mathrm{ARB}=$ angiotensin II receptor blocker, $\mathrm{ASA}=$ acetylsalicylic acid, CYP3A4 = cytochrome P450 3A4, NSAID = non-steroidal anti-inflammatory drug, $\mathrm{SD}=$ standard deviation, $\mathrm{TIA}=$ transient ischemic attack.

*Standardized differences are less sensitive to sample size than traditional hypothesis tests. They provide a measure of the difference between groups divided by the pooled standard deviation; a value greater than $10 \%$ is interpreted as a meaningful difference between the groups.

tIncome was categorized into quintiles of average neighbourhood income on the index date (co-prescription of antibiotic).

$¥$ The date of cohort entry is also referred to as the index date.

$\S$ Charlson Comorbidity Index ${ }^{39,40}$ was calculated using 5 years of data on hospital admissions:

patients who had no admissions were given a score of 0 .

ПAssessed using administrative database codes for the 5 years before the index date.

**Cancers of the esophagus, lung, bowel, liver, pancreas, breast, male or female reproductive organs, as well as leukemia and lymphomas.

t+Includes angina and coronary artery revascularization.

$\ddagger \ddagger$ Assessed using prescriptions for antidiabetic medications.

$\S \S$ Within the 120 days before the index date. statins. ${ }^{46}$ However, the inhibition of CYP3A4 cannot explain the increased risk of statin toxicity observed in our study, because we examined interactions with statins not metabolized by CYP3A4.

A growing body of evidence highlights the role of transporter-mediated mechanisms in such interactions, notably the inhibition of human OATPs. ${ }^{19,47-50}$ Pharmacogenetics research as well as in vitro and clinical drug experiments have shown that reduced activity of OATP1B1 and OATP1B3 is associated with increased systemic exposure of non-CYP3A4-metabolized statins. ${ }^{10,14-16,51,52}$ In addition, we now know that statins are substrates of a liver-specific bile acid transporter known as sodium taurocholate cotransporting polypeptide (NTCP). Available data suggest that nearly $30 \%$ of statin transport into the liver may be mediated by this polypeptide. Thus, observed in vivo inhibitory effects may reflect not only the inhibition of OATP1B1 and OATP1B3, but also the inhibition of NTCP. ${ }^{53,54}$ However, the OATPs are still considered to be the key rate-limiting transporters that govern the hepatic uptake of statins. ${ }^{55}$

\section{Limitations}

Our study's findings must be interpreted in the context of its limitations. Prospective collection of data and independent adjudication of outcomes would be the preferred methodology. However, conduct of such a study might not be possible if physicians were required to intervene after learning about concurrent use of drugs with the potential to interact. The increases in absolute risk are underestimated owing to limited sensitivity of the diagnostic codes. However, we preferentially captured the most severe forms of the conditions (i.e., requiring hospital admission), which made these findings of particular interest to clinicians and policy decision-makers. Our findings can be generalized only to older adults, because younger patients are often healthier and may not be as susceptible to drugdrug interactions. ${ }^{56}$ As with all observational studies, we may have failed to account for important unmeasured confounding variables. Given the complex nature of drug-drug interactions, we also cannot be entirely certain that the observed associations were causal or attributable to the mechanisms we suggest. This limitation may be offset by the comparable usage patterns and risk of adverse events between clarithromycin and azithromycin when used independently, although we did observe a small absolute difference in all-cause mortality with clarithromycin compared with azithromycin in the absence of potentially interacting drugs. ${ }^{32}$ 
Table 2: Outcomes within 30 days after co-prescription of clarithromycin or azithromycin with a statin not metabolized by CYP3A4

\begin{tabular}{|c|c|c|c|c|c|}
\hline \multirow[b]{3}{*}{ Outcome } & \multicolumn{2}{|c|}{ No. of events $(\%)^{*}$} & \multirow{3}{*}{$\begin{array}{c}\text { Absolute } \\
\text { risk difference } \\
(95 \% \mathrm{Cl}), \%\end{array}$} & \multirow{2}{*}{\multicolumn{2}{|c|}{ Relative risk $(95 \% \mathrm{Cl})$}} \\
\hline & \multirow{2}{*}{$\begin{array}{c}\text { Clarithromycin } \\
n=51523\end{array}$} & \multirow{2}{*}{$\begin{array}{c}\text { Azithromycint } \\
n=52518\end{array}$} & & & \\
\hline & & & & Unadjusted & Adjusted $¥$ \\
\hline $\begin{array}{l}\text { Hospital admission with } \\
\text { rhabdomyolysis }\end{array}$ & $13(0.03)$ & $6(0.01)$ & $0.02(-0.03$ to 0.03$)$ & $2.21(0.84$ to 5.81$)$ & 2.27 (0.86 to 5.96$)$ \\
\hline $\begin{array}{l}\text { Hospital admission with } \\
\text { acute kidney injury }\end{array}$ & $175(0.34)$ & $122(0.23)$ & 0.11 (0.04 to 0.17$)$ & 1.46 (1.16 to 1.84$)$ & 1.65 (1.31 to 2.09$)$ \\
\hline $\begin{array}{l}\text { Hospital admission with } \\
\text { hyperkalemia }\end{array}$ & $33(0.06)$ & $18(0.03)$ & 0.03 (0.00 to 0.06$)$ & 1.87 (1.05 to 3.32$)$ & $2.17(1.22$ to 3.86$)$ \\
\hline All-cause mortality & $200(0.39)$ & $155(0.30)$ & 0.09 (0.02 to 0.16$)$ & 1.32 (1.07 to 1.62 ) & $1.43(1.15$ to 1.76$)$ \\
\hline
\end{tabular}

Note: $\mathrm{Cl}=$ confidence interval, CYP3A4 = cytochrome P450 $3 \mathrm{~A} 4$.

*The number of events (and the proportion of patients who experienced an event) for all outcomes except all-cause mortality were assessed with the use of hospital diagnostic codes. This underestimates the true event rate, because these codes have high specificity but low sensitivity.

tPatients prescribed azithromycin served as the referent group.

¥Adjusted for 15 covariates (age, sex, year of cohort entry; baseline evidence of chronic kidney disease, stroke or transient ischemic attack, peripheral vascular disease coronary artery disease, congestive heart failure, major cancer and diabetes; baseline use, in the 120 days before the index date, of $\beta$-blockers, calcium-channel blockers, diuretics, angiotensin-converting-enzyme inhibitors or angiotensin II receptor blockers, and nonsteroidal anti-inflammatory drugs) using logistic regression model (see Methods section). To reduce concerns about model over-fitting, we repeated the analysis adjusting for only age and sex; the results did not differ.

\section{Conclusion}

Co-prescription of clarithromycin and a statin not metabolized by CYP3A4 was associated with a modest increase in the number of deaths and hospital admissions because of adverse events that may reflect statin toxicity among older adults. Although the US FDA recommends the use of non-CYP3A4-metabolized statins as a safer alternative when taken concurrently with CYP3A4 inhibitors, ${ }^{9,50,57}$ our findings indicate that unintended adverse events may still occur, possibly because of additional mechanisms of drug interactions independent of the CYP3A4 pathway. To prevent toxicity, the use of azithromycin or another antibiotic that does not interact with statins can be considered.

\section{References}

1. Ioannidis JP. More than a billion people taking statins? Potential implications of the new cardiovascular guidelines. JAMA 2014; 311:463-4.

2. Baigent C, Blackwell L, Emberson J, et al.; Cholesterol Treatment Trialists' (CTT) Collaboration. Efficacy and safety of more intensive lowering of LDL cholesterol: a meta-analysis of data from 170000 participants in 26 randomised trials. Lancet 2010; 376:1670-81.

3. Cohen JD, Brinton E, Ito M, et al. Understanding Statin Use in America and Gaps in Patient Education (USAGE): an Internetbased survey of 10138 current and former statin users. J Clin Lipidol 2012;6:208-15.

4. Trieu J, Emmett L, Perera C, et al. Rhabdomyolysis resulting from interaction of simvastatin and clarithromycin demonstrated by Tc-99m MDP scintigraphy. Clin Nucl Med 2004;29:803-4.

5. Campbell G, Jayakumar U, Mccracken S, et al. A cautionary tale: delayed onset rhabdomyolysis due to erythromycin/ simvastatin interaction. Age Ageing 2007;36:597.

6. Mah Ming JB, Gill M. Case report: drug-induced rhabdomyolysis after concomitant use of clarithromycin, atorvastatin, and lopinavir/ ritonavir in a patient with HIV. AIDS Patient Care STDS 2003;17:207-10.

7. Mancini GB, Baker S, Bergeron J, et al. Diagnosis, prevention, and management of statin adverse effects and intolerance: proceedings of a Canadian Working Group Consensus Conference. Can J Cardiol 2011;27:635-62.
8. Dresser GK, Spence J, Bailey D. Pharmacokinetic-pharmacodynamic consequences and clinical relevance of cytochrome P450 3A4 inhibition. Clin Pharmacokinet 2000;38:41-57.

9. Kellick KA, Bottorff M, Toth P. A clinician's guide to statin drug-drug interactions. J Clin Lipidol 2014;8:S30-46.

10. Seithel A, Eberl S, Singer K, et al. The influence of macrolide antibiotics on the uptake of organic anions and drugs mediated by OATP1B1 and OATP1B3. Drug Metab Dispos 2007;35:779-86.

11. Niemi M. Role of OATP transporters in the disposition of drugs. Pharmacogenomics 2007;8:787-802.

12. DeGorter MK, Xia C, Yang J, et al. Drug transporters in drug efficacy and toxicity. Annu Rev Pharmacol Toxicol 2012;52:249-73.

13. Higgins JW, Bao J, Ke A, et al. Utility of OATP1A/1B-knockout and OATP1B1/3-humanized mice in the study of OATP-mediated pharmacokinetics and tissue distribution: case studies with pravastatin, atorvastatin, simvastatin, and carboxydichlorofluorescein. Drug Metab Dispos 2014;42:182-92.

14. Choi JH, Lee MG, Cho JY, et al. Influence of OATP1B1 genotype on the pharmacokinetics of rosuvastatin in Koreans. Clin Pharmacol Ther 2008;83:251-7.

15. Niemi M, Schaeffeler E, Lang T, et al. High plasma pravastatin concentrations are associated with single nucleotide polymorphisms and haplotypes of organic anion transporting polypeptide-C (OATP-C, SLCO1B1). Pharmacogenetics 2004;14:429-40.

16. Nishizato Y, Ieiri I, Suzuki H, et al. Polymorphisms of OATP-C (SLC21A6) and OAT3 (SLC22A8) genes: consequences for pravastatin pharmacokinetics. Clin Pharmacol Ther 2003;73: 554-65.

17. Ming EE, Davidson M, Hi S, et al. Concomitant use of statins and CYP3A4 inhibitors in administrative claims and electronic medical records databases. J Clin Lipidol 2008;2:453-63.

18. Gelissen IC, Mclachlan A. The pharmacogenomics of statins. Pharmacol Res 2014;88:99-106.

19. Kalliokoski A, Niemi M. Impact of OATP transporters on pharmacokinetics. Br J Pharmacol 2009;158:693-705.

20. Hanna I, Pelis R. Drug transporters in drug interactions and disposition. In: Zhang D, Surapaneni S, editors. ADME - enabling technologies in drug design and development. Hoboken (NJ): John Wiley \& Sons; 2012:29.

21. Population by sex and age group, by province and territory (number, both sexes), 2014 [Table 051-0001]. Ottawa: Statistics Canada. Available: www.statcan.gc.ca/tables-tableaux/sum-som /101/cst01/demo31a-eng.htm (modified 2014 Sept. 26; accessed 2014 Feb. 14).

22. von Elm E, Altman D, Egger M, et al. The Strengthening the Reporting of Observational Studies in Epidemiology (STROBE) statement: guidelines for reporting observational studies. Prev Med 2007; 45:247-51.

23. Levy AR, O'Brien B, Sellors C, et al. Coding accuracy of administrative drug claims in the Ontario Drug Benefit database. Can J Clin Pharmacol 2003;10:67-71.

24. Patel AM, Shariff S, Bailey D, et al. Statin toxicity from macro- 
lide antibiotic coprescription: a population based cohort study. Ann Intern Med 2013;158:869-76.

25. Zhao YY, Weir M, Manno M, et al. New fibrate use and acute renal outcomes in elderly adults: a population-based study. Ann Intern Med 2012;156:560-9.

26. Shih AW, Weir M, Clemens K, et al. Oral bisphosphonate use in the elderly is not associated with acute kidney injury. Kidney Int 2012;82:903-8.

27. Molnar AO, Coca S, Devereaux P, et al. Statin use associates with a lower incidence of acute kidney injury after major elective surgery. J Am Soc Nephrol 2011;22:939-46.

28. Jain AK, Cuerden M, Mcleod I, et al. Reporting of the estimated glomerular filtration rate was associated with increased use of angiotensin-converting enzyme inhibitors and angiotensin-II receptor blockers in CKD. Kidney Int 2012;81:1248-53.

29. Gandhi S, Fleet J, Bailey D, et al. Calcium-channel blocker clarithromycin drug interactions and acute kidney injury. JAMA 2013;310:2544-53.

30. Pai MP, Graci D, Amsden G. Macrolide drug interactions: an update. Ann Pharmacother 2000;34:495-513.

31. Westphal JF. Macrolide-induced clinically relevant drug interactions with cytochrome P-450A (CYP) 3A4: an update focused on clarithromycin, azithromycin and dirithromycin. $\mathrm{Br} J \mathrm{Clin}$ Pharmacol 2000;50:285-95.

32. Fleet JL, Shariff S, Bailey D, et al. Comparing two types of macrolide antibiotics for the purpose of assessing populationbased drug interactions. BMJ Open 2013;3:pii:e002857.

33. CYP3A and P-gp inhibitors and their relative potency [Table 14]. In: Drug development and drug interactions: table of substrates, inhibitors and inducers. Silver Spring (MD): Food and Drug Administration; 2011. Available: www.fda.gov/drugs/development approvalprocess/developmentresources/druginteractionslabeling /ucm093664.htm\#potency (accessed 2014 Jan. 24)

34. Hartkoorn RC, San Kwan W, Shallcross V, et al. HIV protease inhibitors are substrates for OATP1A2, OATP1B1 and OATP1B3 and lopinavir plasma concentrations are influenced by SLCO1B1 polymorphisms. Pharmacogenet Genomics 2010; 20:112-20

35. Hwang YJ, Shariff S, Gandhi S, et al. Validity of the International Classification of Diseases, Tenth Revision code for acute kidney injury in elderly patients at presentation to the emergency department and at hospital admission. BMJ Open 2012;2: 001821.

36. Fleet JL, Shariff S, Gandhi S, et al. Validity of the International Classification of Diseases 10th revision code for hyperkalaemia in elderly patients at presentation to an emergency department and at hospital admission. BMJ Open 2012;2:e002011.

37. Jha P, Deboer D, Sykora K, et al. Characteristics and mortality outcomes of thrombolysis trial participants and nonparticipants: a population-based comparison. J Am Coll Cardiol 1996;27:1335-42.

38. Mamdani M, Sykora K, Li P, et al. Reader's guide to critical appraisal of cohort studies: 2. Assessing potential for confounding. BMJ 2005;330:960-2.

39. Charlson ME, Pompei P, Ales K, et al. A new method of classifying prognostic comorbidity in longitudinal studies: development and validation. J Chronic Dis 1987;40:373-83.

40. Quan H, Sundararajan V, Halfon P, et al. Coding algorithms for defining comorbidities in ICD-9-CM and ICD-10 administrative data. Med Care 2005;43:1130-9.

41. Repchinsky C, Welbanks L, Bisson R. Compendium of pharmaceuticals and specialties. Ottawa: Canadian Pharmacists Association; 2002.

42. Pharmaceutical trends: top 50 dispensed medications in Canada. Kanata (ON): IMS Health 2010. Available: www.imshealth.com /deployedfiles/ims/Global/North\%20America/Canada/Home\%20 Page\%20Content/Pharma\%20Trends/Top50Dispensed_En_11.pdf (accessed 2014 Jan. 24).

43. Zhou SF. Drugs behave as substrates, inhibitors and inducers of human cytochrome P450 3A4. Curr Drug Metab 2008;9:310-22.

44. Ito K, Ogihara K, Kanamitsu S, et al. Prediction of the in vivo interaction between midazolam and macrolides based on in vitro studies using human liver microsomes. Drug Metab Dispos 2003;31:945-54.

45. Polasek TM, Miners J. Quantitative prediction of macrolide drug-drug interaction potential from in vitro studies using testosterone as the human cytochrome P4503A substrate. Eur $J$ Clin Pharmacol 2006;62:203-8.

46. FDA Drug Safety Communication: Interactions between certain $\mathrm{HIV}$ or hepatitis $\mathrm{C}$ drugs and cholesterol-lowering statin drugs can increase the risk for muscle injury. Silver Spring (MD): US Food and Drug Administration; 2012. Available: www.fda.gov /Drugs/DrugSafety/ucm293877.htm (accessed 2014 Dec. 1).
47. Fahrmayr C, Fromm M, König J. Hepatic OATP and OCT uptake transporters: their role for drug-drug interactions and pharmacogenetic aspects. Drug Metab Rev 2010;42:380-401.

48. Kindla J, Fromm M, König J. In vitro evidence for the role of OATP and OCT uptake transporters in drug-drug interactions. Expert Opin Drug Metab Toxicol 2009;5:489-500.

49. Ho RH, Kim R. Transporters and drug therapy: implications for drug disposition and disease. Clin Pharmacol Ther 2005;78:260-77.

50. Neuvonen PJ, Niemi M, Backman J. Drug interactions with lipid-lowering drugs: mechanisms and clinical relevance. Clin Pharmacol Ther 2006;80:565-81.

51. Simonson SG, Raza A, Martin P, et al. Rosuvastatin pharmacokinetics in heart transplant recipients administered an antirejection regimen including cyclosporine. Clin Pharmacol Ther 2004; 76:167-77

52. Park JW, Siekmeier R, Lattke P, et al. Pharmacokinetics and pharmacodynamics of fluvastatin in heart transplant recipients taking cyclosporine A. J Cardiovasc Pharmacol Ther 2001;6:351-61.

53. Ho RH, Tirona R, Leake B, et al. Drug and bile acid transporters in rosuvastatin hepatic uptake: function, expression, and pharmacogenetics. Gastroenterology 2006;130:1793-806.

54. Bi YA, Qiu X, Rotter C, et al. Quantitative assessment of the contribution of sodium-dependent taurocholate co-transporting polypeptide (NTCP) to the hepatic uptake of rosuvastatin, pitavastatin and fluvastatin. Biopharm Drug Dispos 2013;34:452-61.

55. Shitara Y, Maeda K, Ikejiri K, et al. Clinical significance of organic anion transporting polypeptides (OATPs) in drug disposition: their roles in hepatic clearance and intestinal absorption. Biopharm Drug Dispos 2013;34:45-78.

56. Higashi T, Shekelle P, Solomon D, et al. The quality of pharmacologic care for vulnerable older patients. Ann Intern Med 2004 140:714-20.

57. Biaxin Filmtab (clarithromycin tablets, USP), Biaxin XL Filmtab (clarithromycin extended-release tablets), Biaxin Granules (clarithromycin for oral suspension, USP). Silver Spring (MD): US Food and Drug Administration; 2013. Available: www.fda .gov/Safety/MedWatch/SafetyInformation/ucm258816.htm (accessed 2014 Dec. 9).

Affiliations: Divisions of Nephrology (Li, McArthur, Fleet, Shariff, Gandhi, Dixon, Garg) and Clinical Pharmacology (Kim), Department of Medicine, Western University, London, Ont.; Institute for Clinical Evaluative Sciences (ICES) Western (McArthur, Juurlink, Shariff, Gomes, Dixon, Garg), London, Ont.; Lawson Health Research Institute (Bailey), London Health Sciences Centre, London, Ont.; Sunnybrook Health Sciences Centre (Juurlink), Toronto, Ont.; Li Ka Shing Knowledge Institute (Gomes, Mamdani), St. Michael's Hospital, Toronto, Ont.; Institute of Health Policy, Management and Evaluation (Mamdani), University of Toronto, Toronto, Ont.; Department of Epidemiology and Biostatistics (Gandhi), Western University, London, Ont.

Contributors: Daniel Li and Amit Garg drafted the manuscript. Eric McArthur conducted the statistical analysis. All of the authors contributed to the study concept and design and the interpretation of data, revised the manuscript for important intellectual content, approved the final version submitted for publication and agreed to act as guarantors of the work.

Funding: This study was supported by ICES Western. ICES is funded by an annual grant from the Ontario Ministry of Health and Long-Term Care. Core funding for ICES Western is provided by the Academic Medical Organization of Southwestern Ontario, the Schulich School of Medicine and Dentistry, Western University, and the Lawson Health Research Institute. This project was conducted with members of the provincial ICES Kidney, Dialysis and Transplantation Research Program, which receives programmatic grants from the Canadian Institutes of Health Research. The opinions, results and conclusions are those of the authors and are independent from the funding sources. No endorsement by ICES, the Academic Medical Organization of Southwestern Ontario, the Schulich School of Medicine and Dentistry, Western University, the Lawson Health Research Institute or the Ontario Ministry of Health and Long-Term Care is intended or should be inferred. 